\title{
LEVANTAMENTO DOS ITENS RELACIONADOS À PREVENÇÃO CONTRA INCÊNDIO E PÂNICO EM EDIFICAÇÕES RESIDENCIAIS MULTIFAMILIARES VERTICAIS EM NATAL
}

\author{
D. J. M. LIBERATO ${ }^{1 *}$ e M. F. SOUZA ${ }^{2}$ \\ ${ }^{1}$ Licenciado em Ciências Biológicas, vistoriador do Corpo de Bombeiros Militar do Rio Grande do Norte \\ 2 Professora do Departamento de Microbiologia e Parasitologia, UFRN \\ daniel_liberato@hotmail.com*
}

Artigo submetido em setembro/2014 e aceito em novembro/2015

DOI: 10.15628/holos.2015.2382

\section{RESUMO}

Diante da crescente verticalização em Natal, surge uma preocupação voltada à segurança contra incêndio e pânico. O objetivo deste trabalho foi levantar os itens relacionados à prevenção contra incêndio e pânico mais negligenciados em condomínios residenciais verticais, das zonas Leste e Sul de Natal. Foram pesquisados dados em relatórios de vistorias realizadas pelo Serviço Técnico de Engenharia do CBMRN. Um maior número de itens negligenciados foi observado em edificações sob a administração dos moradores, quando comparados àquelas sob intermediação da construtora (zona Leste, $p<0,05$; zona Sul, $p<0,04)$. Os itens mais negligenciados foram: área de refúgio, compartimentação vertical, escada protegida/convencional, rede de hidrantes $\mathrm{e}$ sinalização.

PALAVRAS-CHAVE: Corpo de Bombeiros, Extintor de incêndio, Rede de hidrantes.

\section{SURVEY OF ITEMS RELATED TO THE PREVENTION OF FIRE AND PANIC IN VERTICAL BUILDINGS MULTIFAMILY RESIDENTIAL IN NATAL CITY}

\begin{abstract}
Given the increasing vertical integration in the city of Natal, comes a concern turned to panic and fire safety. The objective of this study was to survey items related to fire prevention and panic most overlooked in vertical residential developments, the eastern and southern zones of Natal. The data were searched for reports of inspections conducted by the Technical Service Engineering of CBMRN. A greater number of neglected
\end{abstract}

items was observed in buildings under the management of residents when compared to those that were under the intermediation of construction company (east zone, $p<0.05$; south zone, $p<0.04$ ). Rescue platform, vertical partitioning, protected or conventional ladder, hydrant system and emergency signaling have been most overlooked items.

KEYWORDS: Fire department, Fire extinguisher, Hydrant system. 


\section{INTRODUÇÃO}

Desde a última década do milênio a cidade do Natal vem passando por processo de crescimento populacional, passando de um pouco mais de 607 mil habitantes em 1991, para mais de 712 mil habitantes em 2000 e 803.739 mil habitantes em 2010 (IBGE, 2010).

Concomitante a isso vem ocorrendo um crescimento imobiliário considerável, no qual se destaca a verticalização e a popularização da figura do condomínio, com a construção de apartamentos para uso habitacional. A habitação é o local físico onde se desenvolve a vida social e familiar. Onde as pessoas se abrigam, repousam e devem sentir-se seguras. Para isso uma série de elementos deve ser considerada, especialmente quando a unidade residencial está inserida em condomínio vertical.

A prevenção contra incêndio e pânico é um bom exemplo para se refletir sobre a questão de segurança nos condomínios. Dentre as razões para reflexão está a própria situação de um incêndio bem como o elevado número de itens que constituem o rol das recomendações para a prevenção contra incêndio e pânico. $O$ desconhecimento técnico e prático da população quanto a esses itens também é foco de reflexão.

Além disso, há de se considerar que quanto maior a complexidade da edificação, maior será o risco de incêndio. Ou, em outras palavras, quanto mais sofisticadas, maiores e mais altas forem as edificações, mais cuidados são requeridos para a prevenção de incêndios (DEL CARLO, 2008).

De acordo com o Código de Segurança e Prevenção contra Incêndio e Pânico do Estado do Rio Grande do Norte, são necessários dispositivos de proteção contra incêndio para as edificações residenciais multifamiliar, cujas exigências são relacionadas à área construída e à altura da edificação. Os referidos dispositivos de segurança, para as edificações com altura entre 15 e 60 metros de altura, são os que se seguem: área de refúgio, central de gás, chuveiros automáticos, compartimentação vertical, escada protegida, extintores, hidrantes, hidrante público, iluminação de emergência, sinalização e pára-raios.

A área de refúgio, também denominada plataforma de resgate, está situada na cobertura do prédio e é destinada a abrigar os ocupantes da edificação em caso de incêndio. Logo, é necessário que sua porta de acesso esteja sinalizada e de livre acesso, e que existam grampos de salvamento e respectivas proteções contra desgaste por arestas vivas para um possível resgate, via rapel (RIO GRANDE DO NORTE, 1974).

O sistema fixo de combate a incêndio (rede de hidrantes) e o sistema de chuveiros automáticos possuem, cada um, o conjunto moto-bomba, popularmente denominada bomba de incêndio que quando em funcionamento mantém os sistemas pressurizados. As bombas de incêndio e seus quadros de comando devem tanto estar sinalizados especificando a que sistema atende quanto estar em local de fácil acesso, sinalizado, com iluminação convencional e de emergência. O comando deve atender aos modos manual e automático, de forma plena (ABNT, 2001; RIO GRANDE DO NORTE, 1974; SÃO PAULO, 2011a; SÃO PAULO, 2011d).

A central de gás e as caixas de reguladores de segundo estágio de gás dos pavimentos devem possuir suas devidas sinalizações de advertência e não devem ser usadas como depósito para outros objetos. Outro cuidado básico no que se refere à segurança deste local é que a central 
de gás esteja localizada em distâncias de segurança para ralos, esgotos e instalações elétricas. Seu extintor de incêndio específico deve receber a devida atenção, assim como todos os outros extintores do condomínio (ABNT, 2008; RIO GRANDE DO NORTE, 1974).

Todo extintor serve para o combate a princípios de incêndio; deve estar instalado em local e altura adequada e possuir sinalização que o identifique a partir de qualquer ponto da edificação. Precisa ser protegido das intempéries e estar em condições de pleno uso (ABNT, 1995, 2001b, 2010; RIO GRANDE DO NORTE, 1974; SÃO PAULO, 2011c).

No que se refere à compartimentação vertical, trata-se de uma medida de proteção contra incêndio que evita a propagação de fogo, fumaça ou gases de um pavimento para outro, interna ou externamente. Levando em consideração que nos prédios verticais é comum a existência de vãos que unem todos os pavimentos (shafts) com a finalidade de abrigar tubulações hidráulicas e instalações elétricas, é necessário que todos os shafts sejam providos de compartimentação (RIO GRANDE DO NORTE, 1974).

Outro dispositivo importante é a escada protegida a qual é antecedida pela porta cortafogo. Tal dispositivo deve estar devidamente sinalizado e com pleno fechamento automático de modo a evitar passagem de fumaça dos halls dos pavimentos para o corpo da escada. Todas as escadas devem estar livres de equipamentos, possuir corrimãos e piso antiderrapante (ABNT, 1997, 2001a; RIO GRANDE DO NORTE, 1974; SÃO PAULO, 2011b, 2011c).

A rede do sistema fixo de hidrantes precisa passar por periódicas manutenções e inspeções. O local do abrigo das mangueiras deve estar sinalizado, livre de obstáculos e possuir os equipamentos básicos para o combate a incêndio, como mangueiras, chave de mangueiras e esguicho. Os hidrantes de fachada que ficam localizados na calçada do prédio também precisam de cuidados para sua plena identificação e manuseio (ABNT, 2000, 2001b; RIO GRANDE DO NORTE, 1974; SÃO PAULO, 2011c, 2011d).

A iluminação de emergência é um sistema automático que serve para iluminar a rota de fuga e saídas da edificação, facilitando a evacuação segura de pessoas do local sinistrado quando houver falha no suprimento de energia elétrica (RIO GRANDE DO NORTE, 1974).

Também é necessária a existência de sinalização das rotas de fuga, saídas de emergência e disjuntores dos quadros de energia. Quando existirem, os locais dos geradores devem possuir as indicações de advertência, bem como para os elevadores em todos os pavimentos (SÃO PAULO, 2011b, 2011c, 2011e).

No Brasil, infelizmente, tem sido registrada uma série de incêndios em condomínios verticais. Alguns exemplos clássicos podem ser citados, tais como, o edifício Andraus que foi palco de um incêndio em 1972, deixando 16 mortos e 330 feridos. E o edifício Joelma que, também na década de 1970, foi incendiado a partir de um curto circuito. Neste caso, o fogo se espalhou rapidamente pelos pavimentos deixando dezenas de vítimas, principalmente devido à estrutura do prédio que entre outras coisas, impediu o resgate das vítimas, por helicóptero. A tragédia deixou 188 mortos e 345 feridos. Ambos os edifícios situavam-se na cidade de São Paulo.

Em setembro de 2011 houve um incêndio em um dos apartamentos de um condomínio residencial, na zona leste da capital potiguar. Durante o combate ao incêndio, foram utilizados com sucesso: chuveiros automáticos (sprinklers), escada protegida, extintores de incêndio e rede de hidrantes. Entretanto, ficou constatada que houve propagação do incêndio para o pavimento 
superior devido à ausência de compartimentação vertical dos shafts. Houve perda total dos bens materiais da unidade habitacional sinistrada, porém não houve vítimas (SERTEN - CBMRN, 2011).

Mais recentemente, o país lamentou e se solidarizou com a dor da população do município de Santa Maria, Rio Grande do Sul. O incêndio foi na Boate Kiss, na madrugada do dia 27 de janeiro de 2013, causado pelo acendimento de um sinalizador. Este emitiu faíscas que atingiram o teto da boate, incendiando a espuma de isolamento acústico, que não tinha proteção contra fogo. As vítimas fatais foram 242 e mais 116 pessoas feridas. Tais acontecimentos deixam marcas profundas nas vidas de pessoas próximas e distantes, mas também se constituem objeto de discussão e reflexão sobre o assunto (INCÊNDIO, 2013).

Após a ocorrência desta tragédia, houve um abrupto aumento na quantidade de pedidos de fiscalização para os estabelecimentos situados na região metropolitana de Natal com a finalidade de obtenção do Atestado de Vistoria do Corpo de Bombeiros. Tal demanda reforça a idéia de que é necessária a ocorrência de um desastre para, então, se pensar na prevenção contra incêndio.

Também, em 20 de abril de 2013, ocorreu um incêndio em um condomínio residencial, na cidade de Campo Grande, Mato Grosso do Sul. Durante o combate ao incêndio ficou constatado que os extintores encontravam-se vencidos e que existiam irregularidades na rede de hidrantes. Certamente que o funcionamento adequado desses itens de segurança poderia ter contribuído para reduzir os danos materiais ocorridos (ARRUDA; ZOTTINO, 2013).

A prevenção contra incêndios e pânico é orientada por uma série de normas da ABNT, tais como, NBR 12962, que regulamenta inspeção de extintores; a NBR 9077, que fixa as condições exigíveis que as edificações devem possuir em relação às saídas de emergência em edifícios, apenas para exemplificar. A aplicação de tais normas na construção das edificações é objeto de trabalho dos profissionais específicos da área. A fiscalização também fica a cargo de profissionais qualificados para isso. Mas a população, os usuários, os síndicos?

Na realidade, existe um ramo da ciência que cuida especificamente da segurança contra incêndio, bem como existem as pesquisas e as normas. Muito se há produzido sobre prevenção de incêndios em florestas (RODRIGUES, 2008), mas em se tratando de incêndios domiciliares a produção é bem mais restrita.

No contexto dos incêndios domiciliares admite-se que a educação é considerada o elemento chave para a proteção e a prevenção contra incêndio e pânico (SEITO et al., 2008). Sendo assim, a manutenção de sistemas de coleta, tratamento e análise de dados sobre os itens de segurança nas edificações permite organizar programas de proteção, prevenção contra incêndios e de educação voltados para essa temática.

O objetivo deste trabalho foi levantar os itens relacionados à prevenção contra incêndio e pânico mais negligenciados em condomínios residenciais com altura entre 15 e 60 metros, das zonas leste e sul da cidade do Natal.

\section{MÉTODO DO ESTUDO}

Para este estudo foram selecionados relatórios de primeira e segunda Vistoria Técnica, do cadastro do Corpo de Bombeiros Militar do Rio Grande do Norte (CBMRN), realizadas em 
edificações residenciais multifamiliar com altura variando entre 15 e 60 metros, localizadas nas zonas Leste e Sul de Natal.

Os dados da primeira vistoria se referem ao momento em que a empresa do ramo da construção civil se encontra intermediando o processo de regularização do imóvel junto ao CBMRN. Já na segunda vistoria os dados se referem a momentos em que o imóvel é submetido ao processo de renovação de AVCB (Atestado de Vistoria do Corpo de Bombeiros), por solicitação do síndico ou de profissionais ou empresas especializadas no ramo de administração do condomínio.

O primeiro critério utilizado na seleção dos relatórios para a coleta dos dados foi o de que a vistoria tivesse sido realizada pelo autor da referida pesquisa. Porém, devido a limitações em termos do número de relatórios de vistorias realizadas pelo autor foram também coletados dados de relatórios elaborados por membros da equipe de vistoria do Serviço Técnico de Engenharia do CBMRN.

Os relatórios de primeira vistoria das edificações da zona Leste de Natal datavam entre novembro de 2008 e julho de 2012. Já os de primeira vistoria das edificações escolhidas da zona Sul de Natal datavam entre julho de 2010 e setembro de 2012. Foram analisados 15 relatórios de primeira vistoria para cada uma das áreas.

Os relatórios de segunda vistoria das edificações na zona Leste de Natal datavam entre março de 2010 e setembro de 2012; e os da zona Sul, entre julho de 2009 e setembro de 2012. Foram analisados 30 relatórios de segunda vistoria para cada uma das áreas. 0 tamanho da amostra de segunda vistoria se deveu ao fato da maior quantidade de dados disponíveis. A zona Norte e a zona Oeste não foram incluídas nesta pesquisa devido à escassez de edificações, do padrão escolhido, nas referidas áreas.

Dentre os dispositivos de proteção contra incêndio foram escolhidos nove itens norteadores para compor esta pesquisa, cujo critério de escolha foi o fato de serem considerados de maior relevância e facilidade no tocante ao conhecimento geral da população. Os itens norteadores escolhidos foram: a) área de refúgio; b) bombas de incêndio; c) central de gás; d) compartimentação vertical; e) escada protegida / escada convencional; f) extintores; g) iluminação de emergência; h) hidrantes; e i) sinalização. Esses itens foram desmembrados em 39 subitens, conforme quadro abaixo.

Salienta-se que o sistema de cadastro de vistorias técnicas do CBMRN só permite a busca de edificações por meio de três formas, a saber, número do protocolo da vistoria, nome do condomínio, ou nome do proprietário ou construtora. Sendo que, neste último caso, o nome da construtora só aparece nos casos de primeira vistoria, período quando a empresa do setor de construção civil solicita este serviço com a finalidade de receber a liberação do "habite-se" para entrega do prédio aos moradores.

Para este trabalho foram consideradas com muito negligenciadas as ocorrências de não conformidades com percentual igual ou superior a 30,0\%. A análise estatística dos dados foi feita pelo teste de Mann Whitney, utilizando-se o programa BioEstat 5.0, admitindo-se como significativo $p \leq 0,05$.

Quadro: Itens de segurança norteadores e respectivos subitens inspecionados

Itens de segurança

HOLOS, Ano 31, Vol. 6
Subitens inspecionados 


\begin{tabular}{|c|c|}
\hline Área de refúgio & $\begin{array}{l}\text { Alças de salvamento em aço galvanizado } \\
\text { Porta de acesso destrancada e sem obstrução } \\
\text { Proteção contra arestas vivas para alças de salvamento } \\
\text { Sinalização da porta }\end{array}$ \\
\hline \multirow[t]{2}{*}{ Bombas de incêndio } & $\begin{array}{l}\text { Atendem aos modos automático e manual } \\
\text { Bombas de incêndio funcionam nos dois modos } \\
\text { Bombas de incêndio sinalizadas } \\
\text { Bombas e quadros de comando em local de fácil acesso } \\
\text { lluminação convencional e de emergência na casa de bomba } \\
\text { Quadro de comando sinalizado }\end{array}$ \\
\hline & Sinalização do percurso até a casa de bombas e quadro de comando \\
\hline Central de gás & $\begin{array}{l}\text { Central de gás usada como depósito } \\
\text { Extintor da central de gás } \\
\text { Instalações elétricas a um raio de } 1,5 \mathrm{~m} \\
\text { Sinalização da central de gás e das válvulas de segundo estágio } \\
\text { Ralos, esgotos, galerias a um raio de } 1,5 \mathrm{~m}\end{array}$ \\
\hline $\begin{array}{l}\text { Compartimentação } \\
\text { vertical }\end{array}$ & $\begin{array}{l}\text { Proteção mecânica para a compartimentação } \\
\text { Shafts vedados com material certificado }\end{array}$ \\
\hline $\begin{array}{l}\text { Escada protegida ou } \\
\text { convencional }\end{array}$ & $\begin{array}{l}\text { Corrimão contínuo e em ambos os lados } \\
\text { Corrimãos com extremidades voltadas para a parede } \\
\text { Escada livre de obstáculos } \\
\text { Piso antiderrapante } \\
\text { Porta corta-fogo com fechamento automático } \\
\text { Porta corta-fogo sinalizada }\end{array}$ \\
\hline Extintores & $\begin{array}{l}\text { Altura correta não superior a 1,60 m e acesso livre } \\
\text { Sinalização ou proteção contra intempéries } \\
\text { Validade, selo, pressão e lacre dos extintores }\end{array}$ \\
\hline $\begin{array}{l}\text { lluminação de } \\
\text { emergência }\end{array}$ & Iluminação de emergência funcionando \\
\hline Hidrantes & $\begin{array}{l}\text { Acesso ao hidrante livre de obstáculo } \\
\text { Aduchamento correto da mangueira e presença de equipamentos } \\
\text { Existência do plano de manutenção de hidrantes } \\
\text { Hidrante de fachada com fundo drenante e com britas } \\
\text { Junta storz e registro do hidrante de fachada } \\
\text { Sinalização do abrigo de mangueiras } \\
\text { Sinalização do hidrante de fachada }\end{array}$ \\
\hline Sinalização & $\begin{array}{l}\text { Sinalização da casa do gerador } \\
\text { Sinalização das rotas de fuga } \\
\text { Sinalização do elevador } \\
\text { Sinalização dos disjuntores e quadros de energia }\end{array}$ \\
\hline
\end{tabular}

\section{RESULTADOS E DISCUSSÃO}

O total de edificações incluídas neste estudo foi 30 para a primeira vistoria e 60 edificações para a segunda vistoria. O gráfico 1 mostra os dados gerais de não conformidade em ambas as vistorias. Quando foram comparados os dados de primeira vistoria nas zonas Leste e Sul não se observou diferença estatística significativa. De modo semelhante, quando foram comparados os dados de segunda vistoria nessas duas zonas, também não foi observada diferença estatística significativa. Já a comparação entre primeira e segunda vistoria mostrou que ocorreram maior número de casos de não conformidade na segunda vistoria, sendo essa diferença estatisticamente significante, tanto para a zona Leste $(p<0,05)$, como para a zona Sul $(p<0,04)$.

Os dados mostram que na segunda vistoria existiam sete itens na situação de não conformidade (área de refúgio, bomba de incêndio, compartimentação vertical, escada protegida 
ou convencional, hidrantes, iluminação de emergência e sinalização), enquanto na primeira vistoria existiam cinco itens nessa situação (bomba de incêndio, compartimentação vertical, hidrantes, iluminação de emergência e sinalização). O item compartimentação vertical apresentou maior percentagem de não conformidade na primeira vistoria em relação à segunda vistoria, sendo essa diferença estatisticamente significante $(p=0,01)$. Na segunda vistoria, os itens que apresentaram maior percentual de não conformidade em relação à primeira vistoria foram: área de refúgio $(p=0,01)$, escada protegida/convencional $(p=0,03)$ e rede de hidrantes $(p=0,05)$. 0 item sinalização também apresentou maior tendência de não conformidade $(p=0,07)$ na segunda vistoria (Gráfico 1).

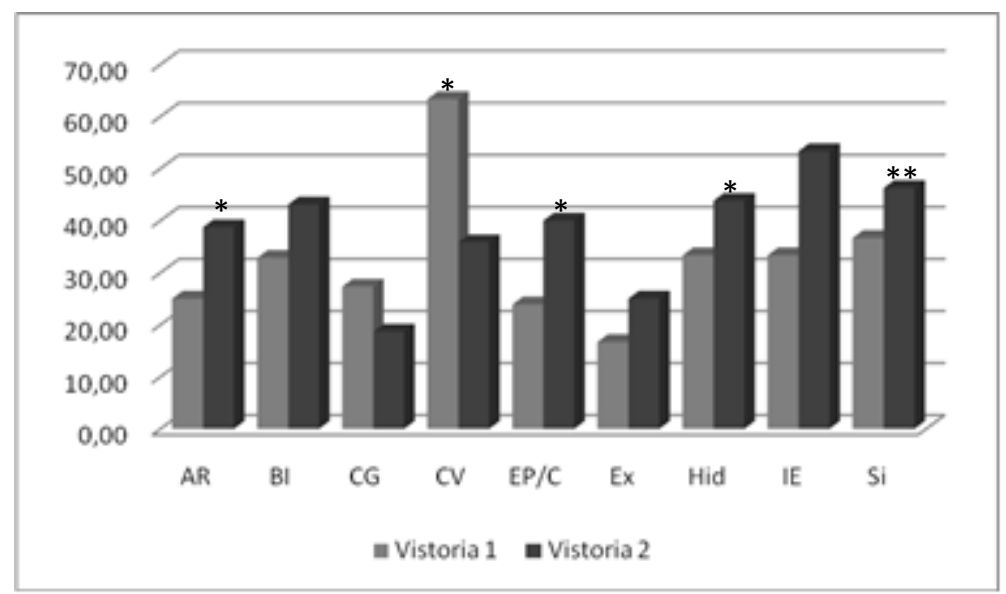

GRÁFICO 1: Percentagem de não conformidade nos itens relacionados à prevenção contra incêndio e pânico em condomínios residenciais entre 15 e 60 de altura situados nas zonas Leste e Sul de Natal, de acordo com a ordem das vistorias realizadas.

Fonte: autoria própria.

Nota:

AR: Área de refúgio*; BI: Bomba de incêndio; CG: Central de gás; CV: Compartimentação vertical*; EP/C: Escada protegida ou convencional*; Ex: Extintores; Hid: Hidrantes*; IE: Iluminação de emergência; Si: Sinalização**. (*p<0,05; $* * p=0,07)$

As percentagens de não conformidade referentes ao item área de refúgio estão representados no gráfico 2, o qual mostra que o percentual geral de não conformidade foi maior na segunda vistoria $(42,0 \%)$ do que na primeira (23,0\%). Tendo ultrapassado o limite de $30,0 \%$ de não conformidade em três dos quatro subitens de segunda vistoria (alças de salvamento em aço galvanizado, proteção contra arestas vivas para alças de salvamento e sinalização da porta).

Nas edificações da zona Sul observou-se que o limite de não conformidade estabelecido neste trabalho também foi ultrapassado nos mesmos três subitens, nas duas vistorias. Isso significa que esse item de segurança tem sido negligenciado, seja pelas construtoras, seja pelos moradores. 


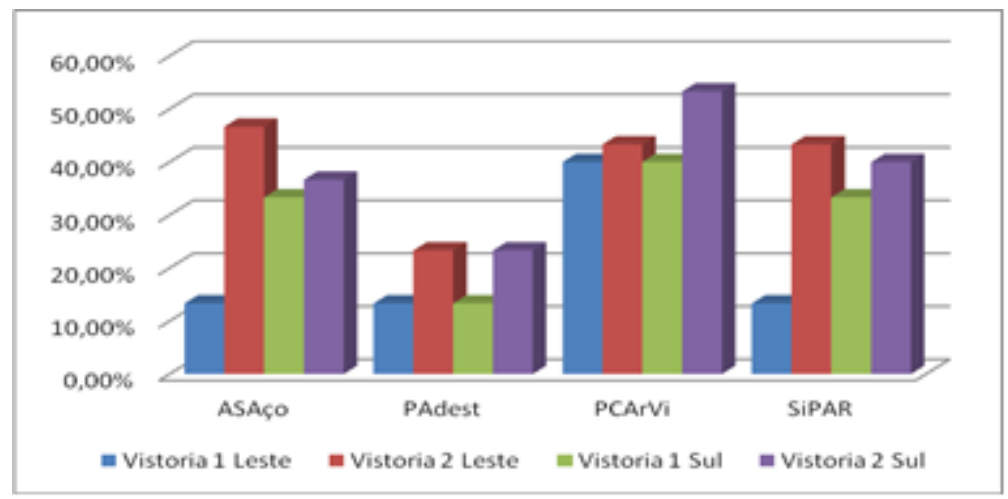

GRÁFICO 2: Percentagem de não conformidade da área de refúgio em edificações vistoriadas pelo Corpo de Bombeiros nas zonas Leste e Sul de Natal.

Fonte: autoria própria.

Nota:

ASAço: Alças de salvamento em aço galvanizado; PAdest: Porta de acesso destrancada / sem obstrução; PCArVi: Proteção contra arestas vivas para alças de salvamento; SiPAR: Sinalização da porta.

O dimensionamento da área de refúgio deve estar previsto em projeto aprovado pelo corpo de bombeiros. É necessário que a referida porta esteja sinalizada com a indicação de "área de refúgio" ou "área de resgate", de modo a indicar o seu acesso e deve permanecer destrancada e livre de qualquer obstáculo. Neste ambiente, os grampos de salvamento, que se encontram afixados na estrutura do piso ou do parapeito, e suas proteções contra desgaste por arestas vivas devem receber tratamento contra as intempéries, mantendo-as então aptas a receberem esforços durante a descida com a vítima. Isto também evita maior redução na resistência dos cabos de salvamento (RIO GRANDE DO NORTE, 1974).

No que se referem aos dados relativos ao item bomba de incêndio e seus subitens, a percentagem geral de não conformidade na segunda vistoria (40,0\%) também foi maior do que na primeira vistoria $(30,0 \%)$. Os subitens, funcionamento das bombas, iluminação da casa de bombas e as sinalizações pertinentes, contribuíram para este maior percentual de não conformidade.

As especificações técnicas e mecanismos de acionamento automático das bombas de incêndio devem ser confirmados junto ao projeto de combate a incêndio aprovado e o percurso de acesso à casa de bombas deve estar sinalizado de modo a facilitar sua localização (ABNT, 2001b; RIO GRANDE DO NORTE, 1974; SÃO PAULO, 2011c).

O modo manual do comando das bombas será utilizado em caso de falhas no funcionamento automático (SÃO PAULO, 2011d). Também é necessária a sinalização dos quadros, com a indicação das posições do comando (automático, neutro e manual) e respectivas botoeiras liga/desliga tipificadas (ABNT, 2001b).

No item central de gás, a percentagem geral de não conformidade na primeira vistoria $(17,0 \%)$ foi maior do que na segunda vistoria $(10,0 \%)$; sendo $80,0 \%$ de não conformidade nos subitens referentes a esse item na zona Leste (central de gás usada como depósito, extintor da central de gás, sinalização da central de gás e das válvulas de segundo estágio e ralos, esgotos, galerias a um raio de $1,5 \mathrm{~m}$ ) e em $40,0 \%$ na zona Sul (extintor da central de gás e ralos, esgotos, galerias a um raio de $1,5 \mathrm{~m}$ ). Isto significa que esse item de segurança tem sido mais negligenciado pelas construtoras do que pelos moradores. Os subitens sinalização da central de gás, válvulas de 
segundo estágio e extintor da central de gás foram os mais negligenciados tanto na primeira quanto na segunda vistoria.

Para as edificações que utilizam o gás liquefeito de petróleo (GLP) como gás combustível, este deve estar armazenado em cilindro com quantidade e localização previamente aprovada. Deverão existir as placas de advertência com as indicações de "perigo", "inflamável" e "proibido fumar" na entrada da central de gás e para as caixas de reguladores de segundo estágio dos pavimentos. Estas também devem ter seus registros sinalizados indicando a que apartamentos atendem. É proibida a existência de qualquer equipamento ou depósito dentro da central de gás, evitando então a obstrução do acesso aos cilindros.

Também é vedada a existência de ralos, esgotos ou caixas de passagem de instalações a um raio de 1,5 $\mathrm{m}$ da central de gás para evitar o acúmulo do GLP nesses ambientes, em caso de vazamento. Por motivo de segurança, é recomendado que não existam instalações elétricas a um raio de $1,5 \mathrm{~m}$ da central de gás com o intuito de evitar possíveis fagulhas nesta área de risco (ABNT, 2008; RIO GRANDE DO NORTE, 1974).

Outro subitem de importância para a casa do gás é o seu extintor de incêndio, os quais devem possuir sinalização que indique o agente extintor e o telefone do corpo de bombeiros. Tal sinalização deverá existir nas quatro faces dos pilares, caso o extintor tenha sido instalado nesta posição, de modo a permitir sua fácil localização.

A instalação do extintor deve obedecer a altura máxima de $1,6 \mathrm{~m}$ e o fundo deve estar no mínimo a 0,1 $\mathrm{m}$ do piso, mesmo que apoiado em suporte. A proteção contra intempéries possui a finalidade de preservá-lo para o adequado acionamento (ABNT, 1995, 2001b, 2010; RIO GRANDE DO NORTE, 1974; SÃO PAULO, 2011c). Os extintores também devem estar lacrados, recarregados, pressurizados, com selo válido do INMETRO (Instituto Nacional de Metrologia, Qualidade e Tecnologia) e anel de validade que garantam suas funcionalidades (RIO GRANDE DO NORTE, 1974).

A falta de sinalização, proteção e manutenção dos extintores, no entanto, parece não ser notada. Isso indica a necessidade de ações educativas destinada principalmente aos usuários, mas também envolvendo outros elos de interesse para a observância deste quesito.

É necessário lembrar que no relatório técnico sobre o acidente ocorrido em janeiro de 2013, na boate Kiss, Santa Maria, Rio Grande do Sul, Brasil, ficou registrado que os extintores localizados próximo ao foco inicial do incêndio não funcionaram, pois apresentaram avarias e falhas. Portanto, o estado desse item de segurança deve ter contribuído negativamente para o resultado final do número de vítimas (CREA-RS, 2013).

No que concerne ao item à compartimentação vertical, um maior percentual de não conformidade foi encontrado na primeira vistoria $(63,0 \%)$ do que na segunda vistoria $(37,0 \%)$, sendo essa diferença estatisticamente significante $(p=0,01)$. Esse quesito também foi mais negligenciado pelas construtoras do que pelos moradores (Gráfico 3). 


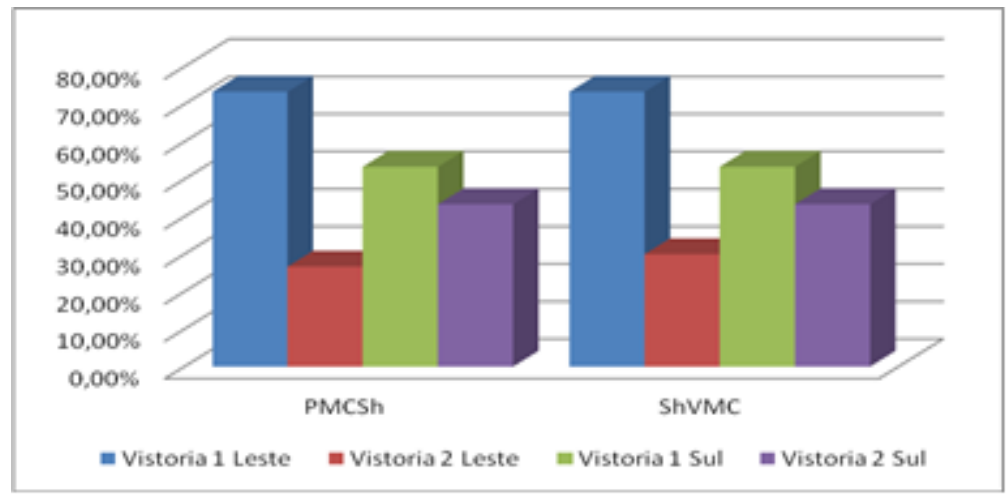

GRÁFICO 3: Percentagem de não conformidade da compartimentação vertical em edificações vistoriadas pelo Corpo de Bombeiros nas zonas Leste e Sul de Natal.

Fonte: autoria própria.

Nota:

PMCSh: Proteção mecânica para a compartimentação; ShVMC: Shafts vedados com material certificado.

Na primeira vistoria, ambos os subitens apresentaram percentagem de não conformidade correspondendo a 73,3\% e 53,3\%, nas zonas Leste e Sul, respectivamente. Na segunda vistoria, ambos os subitens apresentaram percentagem de não conformidade de $43,3 \%$, na zona Sul.

A compartimentação vertical deve ser realizada por material que disponha de certificação sendo resistente a no mínimo duas horas de exposição ao fogo. É recomendável que exista proteção mecânica para preservar o material usado na compartimentação (RIO GRANDE DO NORTE, 1974).

Em prédios verticais, é comum a violação da referida compartimentação vertical dos shafts, por parte dos moradores, para a passagem de fios de instalação de TV a cabo e internet. Por motivo de desconhecimento o morador não se preocupa em preservar a compartimentação vertical.

Com relação à escada protegida/convencional a percentagem de não conformidade na segunda vistoria foi maior do que na primeira vistoria, em $83,3 \%$ dos subitens na zona Leste (corrimão contínuo e em ambos os lados, corrimãos com extremidades voltadas para a parede, escada livre de obstáculos, porta corta-fogo com fechamento automático e porta corta-fogo sinalizada) e em $50 \%$ na zona Sul (corrimão contínuo e em ambos os lados, corrimãos com extremidades voltadas para a parede e escada livre de obstáculos) conforme o Gráfico 4. Este item apresentou diferença estatisticamente significante entre primeira e segunda vistoria $(p<0,03)$, sendo mais negligenciada na segunda vistoria.

Dentre os seis subitens que compõem o item escada protegida/convencional apenas dois, "corrimãos com extremidades voltadas para a parede" e "piso antiderrapante" é que apresentaram percentuais de não conformidade aceitáveis conforme parâmetro estabelecido nesse estudo, em ambas as zonas e vistorias. 


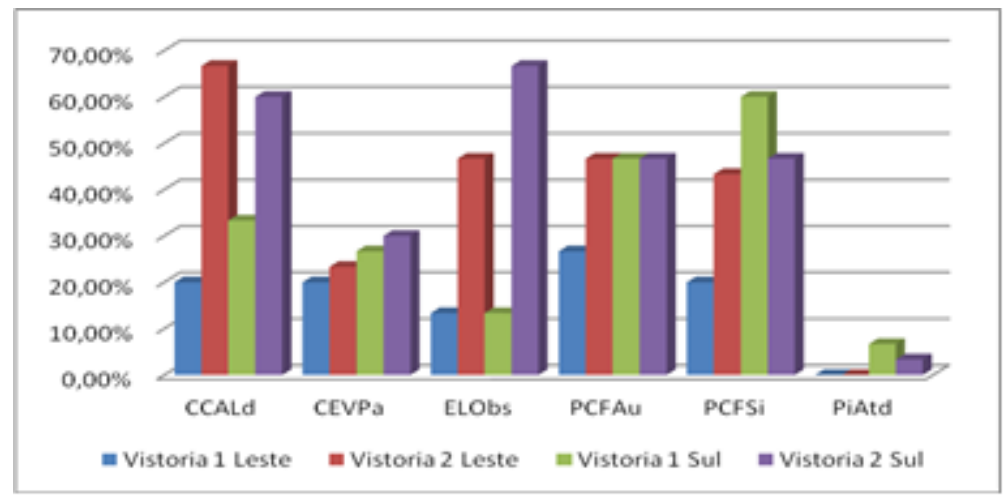

GRÁFICO 4: Percentagem de não conformidade da escada protegida/convencional em edificações vistoriadas pelo Corpo de Bombeiros nas zonas Leste e Sul de Natal.

Fonte: autoria própria.

Nota:

CCALd: Corrimão contínuo e em ambos os lados; CEVPa: Corrimãos com extremidades voltadas para a parede; ELObs: Escada livre de obstáculos; PCFAu: Porta corta-fogo com fechamento automático; PCFSi: Porta corta-fogo sinalizada; PiAtd: Piso antiderrapante.

Os corrimãos devem ser instalados em ambos os lados da escada, contínuos nos patamares retos e possuírem suas extremidades voltadas para a parede (ABNT, 2001a; SÃO PAULO, 2011b). As escadas protegidas por portas corta-fogo devem apresentar ajuste nas molas das dobradiças de modo a permitir fechamento automático. As referidas portas também devem possuir no lado do hall a sinalização "mantenha a porta fechada". Deverá ainda existir no lado da escada a indicação do pavimento a qual facilitará a localização das pessoas quando estiverem utilizando a escada como rota de fuga (ABNT, 1997; RIO GRANDE DO NORTE, 1974; SÃO PAULO, 2011c). Além da não observância desses subitens outro problema que se observou foi a existência de depósitos ou equipamentos no corpo das escadas, os quais obstruem a rota de fuga e servem como material combustível (ABNT, 2001a; RIO GRANDE DO NORTE, 1974).

Pela análise dos dados referentes ao item extintor, foi possível perceber que a percentagem de não conformidade na segunda vistoria $(70,0 \%)$ também foi maior do que na primeira vistoria $(20,0 \%)$, em dois terços dos subitens (altura correta não superior a 1,6 m e acesso livre e validade, selo, pressão e lacre dos extintores), em ambas as zonas.

O subitem "sinalização ou proteção contra intempéries" foi o que apresentou maior percentual de não conformidade, tendo ultrapassado o limite de 30,0\% na primeira e segunda vistoria de ambas as zonas, o que mostra que o quesito sinalização tem sido negligenciado tanto pelas construtoras, quanto pelos moradores.

O subitem "validade, selo, pressão e lacre dos extintores" apesar de ter apresentado certa percentagem de não conformidade em algumas vistorias chegou a ser nula na primeira vistoria da zona Leste. Este subitem além de ser mais conhecido da população é de interesse das empresas que trabalham na manutenção dos extintores. Esses fatores contribuíram para o resultado verificado.

O gráfico 5 mostra que a percentagem de não conformidade dos hidrantes na segunda vistoria $(40,0 \%)$ foi maior do que na primeira vistoria $(27,0 \%)$, em $71,4 \%$ dos subitens referentes aos hidrantes na zona Leste (acesso ao hidrante livre de obstáculo, aduchamento correto da mangueira; presença de equipamentos, existência do plano de manutenção de hidrantes, hidrante 
de fachada com fundo drenante e com britas, e sinalização do abrigo de mangueiras), e em todos os sete, $100,0 \%$, na zona Sul.

Frente aos referidos dados, verifica-se que o sistema da rede de hidrantes dos edifícios estudados apresenta maior negligência no subitem "existência do plano de manutenção de hidrantes", o que demonstra que a manutenção do referido sistema tem sido esquecido por mais de $70,0 \%$ dos administradores dos prédios (construtora ou moradores) estudados na zona Leste e mais de $60,0 \%$ da zona Sul.

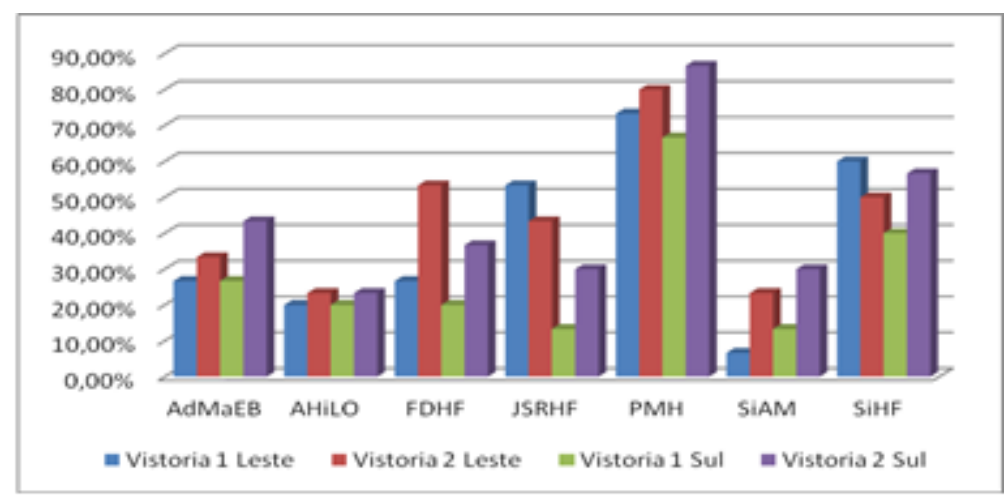

GRÁFICO 5: Percentagem de não conformidade dos hidrantes em edificações vistoriadas pelo Corpo de Bombeiros nas zonas Leste e Sul de Natal.

Fonte: autoria própria.

Nota:

AdMaEB: Aduchamento correto da mangueira e existência de equipamentos básicos no abrigo; AHiLO: Acesso ao hidrante livre de obstáculo; FDHF: Fundo drenante e com britas para o hidrante de fachada; JSRHF: Presença de junta Storz e manutenção de registro do hidrante de fachada; PMH: Existência do plano de manutenção de hidrantes; SiAM: Sinalização do abrigo de mangueiras; SiHF: Sinalização do hidrante de fachada.

O segundo subitem com maior percentual de não conformidade foi "sinalização de hidrante de fachada". Na primeira vistoria observou-se não conformidade de $60,0 \%$ na zona Leste e 40,0\% na zona Sul; e na segunda vistoria, 50,0\% na zona Leste e 56,7\% na zona Sul. Em outras palavras, situações de não conformidade foram observadas em todas as vistorias, em ambas as zonas.

Conforme a NBR 13714, as edificações que dispõem do sistema fixo de combate a incêndio (hidrantes) devem possuir e executar o respectivo plano de manutenção, inclusive com o cronograma de testes e manutenções periódicas para o pleno funcionamento desse sistema (ABNT, 2000; SÃO PAULO, 2011d).

No que referem aos hidrantes de fachada os mesmos devem ser identificados na coloração vermelha e sinalizados indicando a quais redes pertencem (hidrantes ou chuveiros automáticos). Poderão ser utilizados para se acoplarem à viatura de combate a incêndio com a finalidade de pressurização das redes após o consumo de água do reservatório superior. O registro deste hidrante deverá estar em condições de livre acionamento e deverá possuir junta storz do tipo 2 $1 / 2$ " (duas e meia polegadas) para a conexão com a viatura. O fundo do hidrante de fachadas deve ser drenante e o CBMRN recomenda a existência de britas no fundo da caixa deste equipamento (ABNT, 2000; RIO GRANDE DO NORTE, 1974; SÃO PAULO, 2011d).

A rede de hidrantes faz parte do sistema fixo de combate a incêndio da edificação e é usada para combater incêndios de maiores proporções. O abrigo das mangueiras deve estar sinalizado com a indicação "incêndio" ou "hidrante" e a referida sinalização deverá existir em todas as faces 
visíveis de pilares, em caso de hidrante instalado nessa posição (ABNT, 2001b; RIO GRANDE DO NORTE, 1974; SÃO PAULO, 2011c).

As mangueiras devem ser acondicionadas da forma aduchada, ou seja, dobradas ao meio e enroladas a partir da dobra de modo que as duas extremidades permaneçam para o lado de fora do espiral. Este tipo de acomodação evita que a mangueira fique torcida, impedindo o fluxo de água durante um combate a incêndio (RIO GRANDE DO NORTE, 1974).

Os dados referentes à sinalização de emergência nas edificações que se tratam da prevenção de incêndio e pânico encontram-se no gráfico 6 . Por esses dados é possível perceber que a percentagem de não conformidade nas edificações na segunda vistoria $(48,0 \%)$ foi superior ao da primeira vistoria $(33,0 \%)$, sendo essa diferença significativa com valor igual a 0,07 . De todos os quatro subitens deste item, apenas a sinalização da casa do gerador em ambas as vistorias da zona Sul e a sinalização das rotas de fuga na primeira vistoria da zona Leste não apresentaram alta taxa de não conformidade. Já, a sinalização de emergência foi o item com maior percentual de irregularidade

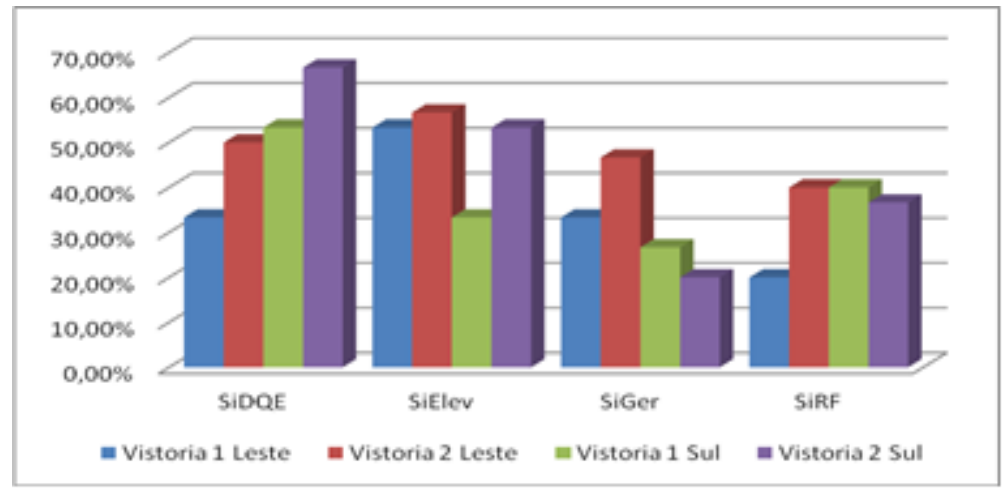

GRÁFICO 6: Percentagem de não conformidade da sinalização em edificações vistoriadas pelo Corpo de Bombeiros nas zonas Leste e Sul de Natal.

Fonte: autoria própria.

Nota:

SiDQE: Sinalização dos disjuntores e quadros de energia; SiElev: Sinalização do elevador; SiGer: Sinalização da casa do gerador; SiRF: Sinalização das rotas de fuga.

A sinalização das rotas de fuga e saídas indica o caminho a ser percorrido para a saída da edificação. Recomenda-se que a mesma seja confeccionada em material fosforescente de modo a facilitar sua visualização mesmo em baixa luminosidade do ambiente (ABNT, 2001b; SÃO PAULO, 2011c).

No tocante aos disjuntores dos quadros de energia, faz-se necessário que todos estejam sinalizados para facilitar a localização e identificação dos circuitos nos casos de emergência (SÃO PAULO, 2011e). Outro tipo de sinalização importante é a que diz respeito às advertências quanto ao uso de elevadores. Recomenda-se que as mesmas existam em todos os andares com a finalidade de instruir seus usuários. As sinalizações são as seguintes: "não usar o elevador em caso de incêndio"; "não exceder a capacidade de carga do elevador"; "não permitir que crianças menores de 10 anos utilizem o elevador quando desacompanhadas de adulto"; e, "antes de entrar no elevador, verifique se a cabina está nivelada".

Quando a edificação dispõe de motogerador de energia, recomenda-se a indicação de "gerador", bem como a sinalização de advertência: "mantenha distância" (SÃO PAULO, 2011e). No 
entanto, na primeira vistoria foi encontrada não conformidade correspondente a 33,3\% na sinalização do gerador; e a $46,6 \%$ na segunda vistoria, ambos na zona Leste.

Pelo que se percebe nesse item, bem como em outros itens e subitens que tratam de sinalização neste estudo, parece existir um hiato para a sua observância. De modo similar também pode ser tratado o subitem "existência de plano de manutenção dos hidrantes". Em ambos os casos fazem-se necessárias ações educativas, para que a importância e significado das sinalizações e da manutenção dos equipamentos de segurança contra incêndio sejam devidamente compreendidos pelos moradores e pelos agentes envolvidos nas construções dessas edificações.

Conforme sugerido por Velho e Magalhães (2006), sinalizar é comunicar a informação a alguém em um determinado espaço; e tempo, a respeito de algum assunto, acrescente-se. A presença e a compreensão prévias das sinalizações e normas técnicas se constituem instrumentos básicos para a organização dos espaços, para a utilização segura das instalações e prevenção contra incêndio e pânico, nas edificações em apreço; e, sobretudo para a preservação da vida.

Como já assinalado anteriormente, sinalizar é um passo básico nessa trajetória de prevenção de incêndio e pânico; que deve ser feito em concomitância ao investimento em um processo educativo, para que se obtenha êxito no alcance à população-alvo. Um exemplo de sucesso nesse sentido foi uma campanha realizada pelos bombeiros locais no ano de 2008, na cidade de Surrey, Colúmbia Britânica, Canadá. A ação baseava-se na entrega porta-a-porta de material educativo para a população, contendo um pacote de informações para esclarecimentos sobre de incêndio residencial. A partir da qual foram evidenciados benefícios, tais como, a redução na frequência e na propagação de incêndios naquela cidade e a melhor aceitação dos detectores de fumaça nas residências (CLARE et al., 2012).

O item iluminação de emergência contém apenas o subitem "iluminação de emergência funcionando" por isso não foi possível proceder a análise estatística dos dados. No tocante ao seu subitem, observou-se negligência tanto na primeira (33,3\% para ambas as zonas) como na segunda vistoria (33,3\%, na zona Leste e 73,3\%, na zona Sul).

O mecanismo de acionamento da iluminação de emergência, seja por bateria autônoma, seja por gerador, deve estar previsto em projeto de combate a incêndio da edificação (RIO GRANDE DO NORTE, 1974). Um requisito importante é que as luminárias de emergência estejam em funcionamento e mantenham a autonomia por duas horas.

De uma forma geral, as razões para as pendências observadas na primeira vistoria estão relacionadas ao fato das construtoras, na pessoa de seus funcionários, se esquecerem de executar algum quesito importante devido à correria e preocupação existente no que se refere à entrega do imóvel; e também pela falta de conhecimento mais profundo na área de prevenção contra incêndio e pânico por parte dos executores. Outra razão é a de que existe uma tendência à economia de gastos o que levaria a construtora a executar somente mediante exigências realizadas pelo órgão competente.

Vale destacar que se realmente existe uma tendência à economia de gastos ou esquecimento no atendimento prévio de algum item de segurança isto acabaria desfavorecendo à construtora. Pois no caso da obra ser encontrada com pendências em vistoria pelo órgão competente e ter que se adequar para obter a liberação, isso exigirá dilatação no prazo para 
entrega dos imóveis aos moradores e, por conseguinte, o descontentamento destes pelo fato de terem que aguardar mais tempo para receberem suas unidades habitacionais.

$O$ atendimento aos itens de segurança em relação à prevenção de incêndio e pânico, para além do cumprimento de normas junto aos órgãos fiscalizadores, pode ser compreendido como um requisito que atribui crédito à construtora. Uma empresa que se antecipa e atende adequadamente a todos os itens de segurança previsto no projeto deve ser reconhecida por isso. Além de que incorporando essa conduta a todas as obras que venha a executar certamente ganhará em tempo para entrega dos bens.

A ideia é que à medida que as pessoas compreendam o significado do devido cumprimento dos itens de segurança contra incêndio e pânico em uma edificação, deverão se tornar mais criteriosas com relação ao imóvel que vão adquirir e com relação à empresa construtora. Em outras palavras, a educação direcionada para essa área poderá reverter o significado de obrigação, para investimento, em relação ao atendimento a esses itens no âmbito da construção civil.

A criação de incentivos para quem antecipadamente atenda aos itens de segurança previsto no projeto e nas normas vigentes torna-se uma saída para se estabelecer diferença entre empresas e empresas. Como por exemplo, a publicação dos nomes das empresas que tiveram mais empreendimentos que receberam AVCB na primeira vistoria dos vistoriadores.

Com relação às não conformidades encontradas em segunda vistoria, as mesmas estão relacionadas à falta de observação, por parte dos vistoriadores, em vistorias anteriores e ao desconhecimento técnico e prático das normas de segurança por parte dos moradores. Por outro lado, a falta de informação e instrução nessa área alia-se à falta de interesse frente a outras prioridades do condomínio, tais como as melhorias e benfeitorias na área de arquitetura do prédio ou as compras de outros artigos de decoração.

No tocante aos itens bomba de incêndio, central de gás e extintor, os mesmos não apresentaram diferença estatística entre as vistorias. O que quer dizer que a atenção a esses itens é mantida mesmo sem o olhar de profissionais especializados. Indicando também que há conhecimento sobre esses itens por parte dos moradores. A despeito disso, verificou-se insuficiência de sinalização.

De qualquer modo esses itens parecem ser bem conhecidos por moradores de condomínios o que pode auxiliar na sua manutenção. De modo similar, o conhecimento a respeito de outros itens de segurança nas habitações mencionado neste trabalho também pode se tornar conhecidos dos moradores; e, por conseguinte, será alvo de manutenção adequada e privilegiada nas edificações verticais.

A deterioração dos equipamentos de segurança nas edificações ocorre naturalmente com o passar do tempo. No entanto, é importante ressaltar que outro fator que contribui para isso é a baixa percepção da importância dos itens para a segurança contra incêndio, ou seja, os moradores não percebem o risco de incêndio nas suas edificações. 


\section{CONCLUSÕES}

Ocorreu um maior percentual de não conformidade na segunda vistoria em relação à primeira, independente da edificação estar localizada na Zona Leste ou Zona Sul; exceto para o item compartimentação vertical.

A proteção contra arestas vivas para alças de salvamento foi o subitem mais negligenciado dentro do item área de refúgio, em todas as vistorias. O funcionamento das bombas de incêndio nos modos automático e manual e a existência de iluminação convencional e de emergência foram os subitens com maior percentual de não conformidade, no item bomba de incêndio. Dos seis subitens do item escada protegida/convencional, o único que apresentou percentual de conformidade próximo ao desejável foi a presença de piso antiderrapante. No item hidrante, o maior percentual de não conformidade foi a ausência do plano de manutenção dos hidrantes. A iluminação de emergência apresentou alto grau de não conformidade em todas as vistorias, independente da localização do imóvel.

Os subitens referentes às sinalizações de advertência apresentaram tendência de altos níveis de não conformidade, a saber: sinalização do percurso até a casa de bomba/quadro de comando, central de gás e válvulas de $2^{\circ}$ estágio, da porta corta-fogo da escada protegida, dos extintores, dos hidrantes de fachada, dos disjuntores e quadros de energia, do elevador, da casa do gerador e das rotas de fuga.

Há uma necessidade urgente de um trabalho de educação para a prevenção de incêndio e redução de danos dirigida à população de moradores atuais e futuros das edificações verticais da cidade de Natal.

\section{AGRADECIMENTOS}

Ao Capitão BM Edson Modesto de Oliveira Junior, do Corpo de Bombeiros Militar do Rio Grande do Norte e à professora Renata Antonaci Gama, do Departamento de Microbiologia e Parasitologia da UFRN.

\section{REFERÊNCIAS}

1. ARRUDA, D.; ZOTTINO, T. Apartamento pega fogo; extintores estavam vencidos. Correio do Estado. Campo Grande, Mato Grosso do Sul, 2013. Disponível em: <http://www.correiodoestado.com.br/noticias/apartamento-pega-fogo-extintores-estavamvencidos_180194/>. Acesso em: 19 jan. 2014.

2. ASSOCIAÇÃO BRASILEIRA DE NORMAS TÉCNICAS. NBR 9077: saídas de emergência em edifícios. Rio de Janeiro, 2001a.

3. NBR 13435: sinalização de segurança contra incêndio e pânico. Rio de Janeiro, 1995.

4. . NBR 11742: porta corta-fogo para saída de emergência. Rio de Janeiro, 1997.

5. NBR 13714: sistemas de hidrantes e de mangotinhos para combate a incêndio. Rio de Janeiro, 2000.

6. . NBR 13434: sinalização de segurança contra incêndio e pânico - parte 1: princípios de 
projeto. Rio de Janeiro, 2001b.

7. NBR 13434: sinalização de segurança contra incêndio e pânico - parte 2: símbolos e suas formas, dimensões e cores. Rio de Janeiro, 2004.

8. NBR 13523: central de gás liquefeito de petróleo. Rio de Janeiro, 2008.

9. NBR 12693: sistemas de proteção por extintores de incêndio. Rio de Janeiro, 2010.

10. CLARE, J. et al. Reduced frequency and severity of residential fires following delivery of fire prevention education by on-duty fire fighters: Cluster randomized controlled study. Journal of Safety Research, [S.I.], v. 43, p. 123-128, 2012.

11. CONSELHO REGIONAL DE ENGENHARIA E AGRONOMIA DO RIO GRANDE DO SUL. Análise do sinistro na boate Kiss, em Santa Maria, RS. Relatório técnico: Comissão Especial do CREA-RS. Porto Alegre: CREA-RS, 2013. 31 p.

12. DEL CARLO, U. A segurança contra incêndio no Brasil. In: SEITO, A. I., et al. (Ed). A Segurança contra incêndio no Brasil. São Paulo: Projeto Editora, 2008. p. 9-17.

13. INCÊNDIO na boate Kiss. In: WIKIPÉDIA: a enciclopédia livre, 2013. Disponível em: <http://pt.wikipedia.org/wiki/Incêndio_na_boate_Kiss>. Acesso em: 19 jan. 2014.

14. INSTITUTO BRASILEIRO DE GEOGRAFIA E ESTATÍSTICA. Sinopse do Censo Demográfico 2010: Rio Grande do Norte. [S.I.], 2010. Disponível em: <http://www.censo2010.ibge.gov.br/si nopse/index.php?uf=24\&dados=29 >. Acesso em: 6 jan. 2014.

15. RIO GRANDE DO NORTE. Lei no 4436, de 6 de dezembro de 1974. Código de Segurança e Prevenção contra Incêndio e Pânico do Estado do Rio Grande do Norte. Disponível em: <http://www.cbm.rn.gov.br/contentproducao/aplicacao/sesed_cbm/instituicao/gerados/me moriais_codigo.asp>. Acesso em 6 jan. 2014.

16. RODRIGUES, A. N. C. Considerações sobre prevenção e combate aos incêndios florestais no Estado do Rio de Janeiro. 2008. 24 f. Monografia (Graduação em Engenharia Florestal) - Curso de Engenharia Florestal, Departamento de Silvicultura, Instituto das Florestas, Universidade Federal Rural do Rio de Janeiro, Rio de Janeiro, 2008.

17. SÃO PAULO. (Estado). Polícia Militar do Estado de São Paulo. Corpo de Bombeiros. Instrução Técnica no 09/2011a: compartimentação horizontal e vertical. Disponível em: <http://www. corpodebombeiros.sp.gov.br/dsci_publicacoes2/_lib/file/doc/IT_09_2011.pdf>. Acesso em 6 jan. 2014.

18.

Instrução Técnica № 11/2011b: saídas de emergência. Disponível em: <http://www .corpodebombeiros.sp.gov.br/dsci_publicacoes2/_lib/file/doc/IT_11_2011.pdf>. Acesso em 6 jan. 2014.

19. Instrução Técnica № 20/2011c: sinalização de emergência. Disponível em: <http://w ww.corpodebombeiros.sp.gov.br/dsci_publicacoes2/_lib/file/doc/IT_20_2011.pdf>. Acesso em 6 jan. 2014.

20. Instrução Técnica № 22/2011d: sistemas de hidrantes e de mangotinhos para combate a incêndio. Disponível em: <http://www.corpodebombeiros.sp.gov.br/dsci_publica coes2/_lib/file/doc/IT_22_2011.pdf>. Acesso em 6 jan. 2014.

21. Instrução Técnica no 41/2011e: inspeção visual em instalações elétricas de baixa tensão. Disponível em: <http://www.corpodebombeiros.sp.gov.br/dsci_publicacoes2/_lib/ 
file/doc/IT_41_2011.pdf>. Acesso em 6 jan. 2014.

22. SEITO, Alexandre Itiu. et al. A Segurança contra incêndio no Brasil. São Paulo: Projeto Editora, 2008.

23. SERVIÇO TÉCNICO DE ENGENHARIA DO CORPO DE BOMBEIROS MILITAR DO RIO GRANDE DO NORTE. Relatório de Vistoria Técnica no 130/2011. Natal: CBMRN, 2011. 7 p.

24. VELHO, A. L.; MAGALHÃES, C. F. Sinalizar é comunicar a informação a alguém, em um determinado espaço. In: CONGRESSO BRASILEIRO DE PESQUISA E DESENVOLVIMENTO DE DESIGN, 7., 2006, Paraná. Anais... Paraná. Disponível em: <https://www.academia.edu /Download>. Acesso em 12 jan. 2014. 